\title{
Putting US Back in Museums: Increasing Student Engagement via Experiential Learning Writing Assignments
}

\author{
Rachael Zeleny* \\ $10 / 1 / 2020^{\dagger}$
}

\begin{abstract}
This paper details the evolution of a course, Arts and Society, and the inception of a student-centered assignment, "Putting US back in Museums." By tapping into a nationwide discussion of inclusion and public spaces, this businessproposal-style assignment asks students to consider their own observations as museum visitors alongside research on community engagement, diversity and accessibility. Students aim to identify a specific issue within a museum and to propose change. Throughout the project, students are supported by the implementation of smaller scaffolding assignments, in-class discussions, an embedded librarian, and an assigned writing fellow. Furthermore, they meet at least eight professionals in the field and visit at least four different local sites. This assignment demonstrates best practices via scaffolding, institutional support, experiential learning, and engagement with the local community.
\end{abstract}

\section{Course Context}

The course, "Artivism: An Introduction to Arts and Society," is a writing-intensive, general education course taught in person. ${ }^{1}$ This course is required for our Integrated Arts majors, but it is also a popular elective for other students. By visiting local museums and meeting with museum staff, students examine how museums function rhetorically, giving voice and visibility to certain populations while excluding others. Throughout the course, students complete smaller assignments and participate in class discussions that enrich the depth

\footnotetext{
*University of Baltimore, rzeleny@ubalt.edu. Copyright 2020 Rachael Zeleny. This work is licensed under a Creative Commons Attribution-NonCommercial 4.0 International License (http://creativecommons.org/licenses/by-nc/4.0/).

${ }^{\dagger}$ Submitted, 5/30/19; Accepted, 5/4/20.
} 
of their final project. As their final project, students identify a specific problem within a museum exhibit and propose changes. Following a traditional business proposal format, students write to an institutional leader, in this case a specific individual working for a museum, typically a curator or public engagement director. The first section of their paper addresses the problem they found as related to one of the following issues: a) diversity b) accessibility or c) public engagement. In the next section, by conducting research, they address how other institutions have handled similar problems in a literature review. In the following section, they propose detailed changes. As the final piece to this proposal, they suggest an event that would help to promote the revised exhibit (e.g. a launch party, a musical guest, a workshop for children). I then invite curators and other professionals to attend class and the students pitch their proposals to the museum professionals. Students prepare a five-minute presentation and a visual aid to assist them in making their arguments. Many of them have chosen to create dioramas of their new spaces, while others who are gifted technologically have created virtual renderings of their spaces either via graphically-designed images or in virtual 3-D models.

The use of writing in this course is twofold. On the one hand, students are writing to learn. For each onsite visit, they are required to write reflectively (four separate two-page reflections). These documents incorporate observations and photographs, recording the degree to which they believe the museum succeeds in three areas: 1) engaging and welcoming the local community, 2) demonstrating a commitment to diversity in both hiring practices and art displayed, and 3) accommodating those with diverse abilities.

On the other hand, students are also learning to write for an authentic situation. During the course, they will have met many of the individuals who work at our museums, and they understand that these individuals (or individuals like them) are people who could enact or propose change. They are consistently reading materials created by activists and museum professionals to familiarize themselves with tone and content of such work. With this audience in mind, they ultimately develop a proposal which includes an overview of the problem, a literature review of how other institutions have handled similar issues, and a plan to revise one particular exhibit.

\section{Artistic License: Considering Your Students When Designing Assignments}

The most interesting thing about this assignment is how and why it evolved. At my former institution, I was a Writing Program Administrator. In my current position, I operate in two separate departments: English and Integrated Arts. The "Arts and Society" course is housed in the Integrated Arts program, a program designed for students who will work in the arts industry or who will be managing themselves as artists. Prior to my modifications, the course was a fairly straightforward exploration of key artistic periods.

In an effort to offer more experiential learning opportunities, I decided to take advantage 
of our campus's proximity to key artistic locations. For my first excursion, I took the students to the Walters Art Museum (walkable from campus), and I asked them to conduct a rhetorical analysis of the Renaissance exhibit, using visual clues to identify the arguments about identity and class during this time. But as I followed them through the exhibit, a much more interesting conversation emerged.

First, most of them told me that even though they were from Baltimore, they had never been to the Walters. Second, there were those who indicated they felt uncomfortable in museums. Memorably, one student said, "The people on the walls and the people in the halls, they don't look like me. This place wasn't made for us." However, they also commented that even though there was some discomfort, they loved being outside the classroom.

My overhaul of the curriculum began that evening.

\section{Broad Strokes: Making the Assignment}

I knew I wanted to incorporate reflective writing as a means of asserting that each student's experience of a space was valid and deserved an audience. Thus, in the short papers attached to each visit, students refer to their own life experiences, their experiences as a patron, and perhaps their own work experience in order to assess where a museum has clearly made effort to improve its practices and where a museum could improve. In these documents, students often embed images as evidence. For instance, one student included a photograph of an expensive café menu to comment on the impractical nature of affording such options as a single mother, while another student who also worked as a contractor focused on steps that were aesthetic but clearly difficult to navigate physically.

I also encourage students to include information they can find from the museum's materials, such as the website, brochures and maps. I provide the questions below to guide their analyses:

\section{Accessibility}

- How easy is it to park?

- Are elevators easy to find?

- Are signs/labels easy to read? Braille offered? Audioguides? Alternative languages?

- Is there enough room in every exhibit for a stroller or a wheelchair?

- Does the museum offer sound-reducing headphones/weighted covers/stimulation maps?

- Are there certain days/tour guides available for persons who need additional assistance?

- Are there locations for resting and sitting?

- Does the museum offer gender neutral restrooms/spaces for breastfeeding?

Inclusion 
- Does the art represent diverse populations?

- Does the museum represent diverse artists?

- Does the museum hire a diverse staff (at all levels! You may need to look at the website to learn more about curators, board members, etc)?

- Does the museum offer scholarships/internships/volunteer opportunities that encourage diverse applicants?

- Does the museum showcase artist talks, workshops, and other special activities that would cater towards celebrating diversity?

- Does the staff seem welcoming to all patrons?

\section{Public Engagement}

- Does the museum work to showcase artists/events that align with community interests?

- Does the museum offer activities for families/children?

- Is the museum affordable (consider museum fees, café prices, parking fees, the cost of souvenirs)?

- Where and how does the museum advertise exhibits and events?

- Does the museum offer opportunities to interact with art ("please touch" exhibits)?

- Does the museum offer interactive technology?

- Does the museum have a place for public feedback or suggestions?

These small reflections set them up for the final proposal project. In designing it, I talked with museum professionals and asked them what types of information they needed in order to propose a change. As a result of these conversations, I created the business proposal prompt which asks students to investigate one of the problems identified in one of their earlier assignments (using their images and other primary source material as evidence), then research potential solutions, and finally, to suggest a change. In this document, they should write for a museum professional as if they belonged to the museum community. ${ }^{2}$

\section{Priming the Canvas: Before the Assignment}

Before the semester begins, I plan four visits to four different museums - the American Visionary Art Museum, the Reginald F. Lewis Museum, the Walters Art Museum, and the National Great Blacks in Wax Museum. For each visit, I contact the museum in advance to determine which staff members are best suited for interaction with my class. I look for those who have either worked with public outreach initiatives or curators who have shown interest in diversifying the gallery. For instance, the Walters Art Museum held an exhibition called "Revealing the African Presence in Renaissance Europe," and I asked that curator to talk to my students about the process of designing an exhibit of this kind. At other locations, I ask staff members to talk more broadly about their mission and public engagement initiatives. 
Notably, I also ask the class to download a phone app called "Remind." Since we are moving around constantly during the class, I wanted a mechanism that would allow consistent dialogue between myself and the students. Remind allows you to send messages directly to a student's phone and vice versa. The messages can include images and links, which is very helpful when the students want to show me something they have seen while visiting a museum. Remind allows you to set up virtual "office hours," too, so a student knows not to expect answers immediately. I have had students from two years ago who are still sending links to either just me or to the entire class extending our dialogue way beyond the constraints of a semester-long class.

For day one of class, I create a tug-of-war style discussion using the statement "Museums are made for everyone." For this discussion strategy, this statement is written on the board with a Yes-No-In-between spectrum created underneath:

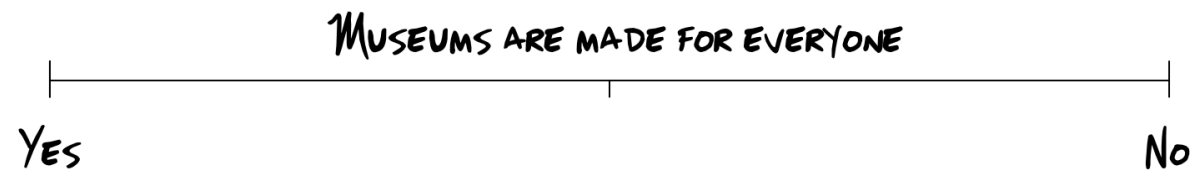

Figure 1:

Students write their names on a post-it note and place it on the spectrum above the line. The class is then divided so that those who answered "no" go to one side of the room and those who said "yes" go to the other. Each group makes a list of as many reasons or experiences they can to justify their response. They record one reason per post-it. Then, they rank their answers so that the most compelling answers go closest to the "yes" or "no" ends, while the less compelling answers go towards the middle. For example:

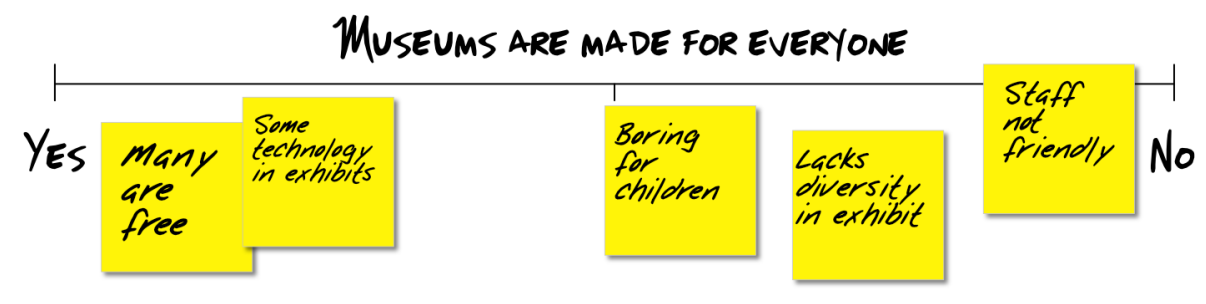

Figure 2:

As the discussion evolves, many comments about racial tension echo what I heard in the Walters Art Museum. Parents lament the difficulty of engaging a teenager immersed in a phone. Students with physical disabilities often note the lack of places to rest. We discuss 
how museums are often overwhelming for individuals on the autism spectrum, and they are surprised to learn about how museums have made significant improvements in this area (see Shrikant, 2018). Students reevaluate their stances to see if they have altered their positions. This dialogue establishes the idea that everyone experiences museums differently.

To show my students how their observations fit into our current moment, I introduce them to a current initiative titled "Museums are not Neutral," founded by museum activists LaTanya Autry and Mike Murawski. Autry (n.d.) writes,

[Museums] are political constructs. Their ongoing practices also are rooted in power. The very fact that this field has a long history of excluding and marginalizing people of color in terms of selection, interpretation, and care of art and other objects, jobs, visitor services, board representation, and more indicates that museums are political spaces. Everything in them and about them involves decisions. (para. 1)

I explain that our class will not only assume that museums can improve with regards to racial diversity but also in regards to other issues of inclusion. I show them some of the databases that are dedicated to this issue. For instance, I show them the list of resources Autry provided that demonstrate social justice intersects with museums' practices. The goal is for students to realize that this conversation is timely and important, and that each of them is in a position to be an agent of change.

In a flipped classroom model, students read the articles at home to prepare for each visit. I choose articles that align with each space's mission or recent initiatives. For instance, for the Baltimore Museum of Art (BMA), I chose three readings: 1) a newspaper article discussing the BMA's radical decision to sell the works of some major art titans in order to create a "war chest" of funds to be used "to fund future acquisitions of cutting-edge contemporary art, specifically by women and artists of color" (Halperin, 2018), 2) Autry's (n.d.) blog discussing the need for museums to improve diversity, and 3) an article that discusses the importance of retraining security guards to be welcoming to all patrons (Luppi, 2014). For the American Visionary Art museum, I distributed their "Seven Educational Goals" and an article about the importance of art as therapy for inmates, "The effectiveness of art therapy in reducing depression in prison populations" (Gussak, 2007). Ultimately, the goal is to provide at least one article that deals with the particular museum and others that can help students situate the issue within a larger dialogue. Many of them use at least some of these sources in their papers.

\section{Supporting the Process}

Once students have visited all of the locations, they either meet with me in person or have phone conferences for further planning. During these conferences, I learn more about their 
personal interests and assist them in shaping the specificity of their chosen issue.

The earlier reflections prepare the students well for the first part of the essay, which is to outline the problem. Most of them have enough material from their initial visit to the museum to structure this section.

Then, we have two in-class sessions designed to assist students with finding sources for the literature review section. Navigating museum blogs or sites dedicated to museum activism or education has proven to be a much different process from a database search. This process is streamlined by creating resource guides and by including a librarian in both of our research sessions. We discuss how the language and tone of these resources will be similar to the tone students should employ in their essays.

Next, I conduct a class on how to write a literature review. First, I show them an example of a successful review. Then, I present a faulty model where several pieces of information are loosely related to the topic but are actually too far away to be helpful in solving the problem. Students are required to find and cut the extraneous pieces. Then, I give them a literature review with ineffective organization. I ask students to physically cut the sentences and restructure the information to be more persuasive. Finally, students bring in their own literature review, and we workshop them using the same techniques. What was once the most difficult part of this assignment has been greatly improved by employing these scaffolding steps.

As a means for brainstorming and editing, my students also meet twice with the writing fellow who is attached to our course. In the first meeting, the fellow assists them with how to write a literature review and how to organize their proposal into the required sections. During the second meeting, students come with a complete draft, and the fellow assists with both global and local changes.

\section{On Display: Assessing the Project}

Students understand that the most important aspect of this assignment is to establish themselves as someone who is entitled to critique and comment on museum spaces. Their written work is graded on the following criteria: 1) Specificity 2) Organization 3) Incorporation of Evidence 4) Originality of Ideas 4) Adherence to APA 5) Use of Images 6) Meeting with Librarian and Writing Fellow.

I now include a presentation and judging component to enhance the authenticity of the experience. Students convert their proposals into five-minute speeches, accompanied by visual aids. Museum professionals and university administrators agree to judge student projects on the following: 1) professionalism, 2) aesthetics of model, 3) creativity of revision, and 4) realism of suggestion. Each student interacts with three judges. The judges attend class and the students are each given a table and they create name tents for their locations 
to be found easily by the judges. The judges are given the names of "their" students at the beginning of class. Each student interacts with three judges. The judges record scores and submit to me for tallying. I announce the winner in the next class. While I have taught this class without this component, I see a dramatic increase in the level of engagement and the quality of the projects by having this step.

\section{A Gallery of Success: Snapshot of Student Work}

The diversity of projects has been incredible. For example, one student dedicated a project to her sister who had just given birth at the beginning of the semester. She found an African statue of a new mother at the BMA and proposed an exhibit that not only featured this statue but also provided a comfortable location for breastfeeding. Another student decided to revise a space for the American Visionary Art Museum. After visiting with his son, he noted that the art was very appealing to children - it is made from found objects and other interesting materials - but that there was not a place for children to play. His revision included a playground where the equipment was made from found objects. $\mathrm{He}$ noted that the designs would be especially tailored for those with disabilities since the museum endorses art as therapy. In a particularly delicious revision, a student tackled the historic Hackerman House, which is attached to the Walters Art Museum. Having just opened last summer, this house features a room dedicated to Sybby Grant, a woman enslaved there in the 1800s. My student felt that the room overlooked the opportunity to discuss cooking as a form of literacy. She suggested that the room should not only showcase Sybby's recipes more prominently but also to have cooked dishes in the room to add a sensory component to the space.

\section{Experiential Learning: Using a City as Classroom}

Through this class and my own research, I have learned that more and more universities are relying on relationships with museums as a means for enhancing curriculum because these locations facilitate a knowledge-based learning economy, improving success and retention (Packer \& Ballantyne, 2002). By incorporating museums into student learning, we introduce students to a "resource for lifelong learning" while also allowing "instructors to move away from chalk and talk, increase student engagement, increase content-relevance, provide in-depth coverage of certain areas and improve proficiencies" (Das, 2015, p. 72). In other words, the success of this class has helped me to confirm that even in this digital age, many students want, and will better succeed, in a class that will connect them to their classmates, their instructor, and to their community.

I continue to see benefits of this assignment. The class average has yet to go below a ninety three percent. The quality of writing for these papers is some of the best I have 
seen in my career. In a record-breaking event, my writing fellow recorded one hundred and eighty-three writing consultations with my twenty-six students, even though only fifty-two of those visits were mandatory. Also my students continue to use the Remind app after the course is over, taking pictures of themselves at museums, and sending links to events that they think could be interesting for the class. Often, the images showcase students with their families, demonstrating the degree to which the boundary between my students and these institutions has begun to dissolve. In my evaluations, students have noted that this is some of the "easiest" writing they have ever done because they actually cared about solving the problem instead of just finishing the assignment. Perhaps my favorite comment was the student who noted that "my white ass" was her "key to the city." In person, she shared that she was able to see how the conversations we were having in class extended to conversations about who had access to academic spaces.

I look forward to hearing the thoughts of the readers. To contact me, write to rzeleny@ubalt.edu, or you can follow some of my teaching adventures at rachaelmzeleny.com.

\section{Assignment: Museums Are Not Neutral}

(To view a PDF facsimile of the original formatting of this assignment, return to this article's homepage and locate the link to the "Assignment" PDF.)

\section{Overview}

You will visit the local museums (at least two). While you will need to take notes on each museum, your paper will focus on how you could revise one exhibit to improve either a) diversity b) accessibility or c) public engagement. Consider an event that would help you promote your revised exhibit. And finally, reflect on this experience.

\section{Section 1}

Describe the current exhibit, the goals of the exhibit, the types of artists, and the types of art displayed in the exhibit. Consider the strengths and limitations of this exhibit. Don't just make generalizations such as "they should have more wheelchair ramps" or "they could give more informative plaques." Which exhibits? Where exactly? What kind of info? 


\section{Section 2}

Using at least 4 outside sources, provide a literature review that outlines how other institutions have handled similar problems. Suggested resources: https://artmuseumteaching.com/ 2017/08/31/museums-are-not-neutral/

\section{Section 3}

Describe your revised exhibit. Detail what artifacts would be included, what you have done to ensure a commitment to diversity, and what you would do to make the exhibit more accessible to those with disabilities.

\section{Section 4}

Describe an event/workshop/kid-friendly activity that would supplement your exhibit. Be specific in your targeted audience, how you would market the event, who might sponsor it, and the purpose of this event.

\section{Section 5}

Reflect on the experience of attending these museums and participating in this project. How has this changed the way you experience museums? Has this project changed the likelihood of you visiting a museum in the future? How has this class impacted your thinking about arts and society?

\section{Writing Requirements}

- 6 pages (not including images), Times New Roman, Double Spaced, MLA citation, at least TWO sources

\section{- Note: You MUST visit a museum to complete this project}

- Image Requirement for slides:

- At least 2 images, at least 720 dpi, no bigger than 1.5 by 1.5 inches, captions clarifying content 


\section{Notes}

\footnotetext{
${ }^{1}$ I have taught a version of this class online, and I am more than happy to discuss modifications to this material for anyone who wishes to do so. Please contact me at rzeleny@ubalt.edu

${ }^{2}$ Notably, this proposal does not include the financial obligation, as these numbers would be too difficult for students to obtain at this stage. I have begun conversations regarding the possibility of linking this course to a business class so that we might do this part better and increase the authenticity of the assignment.
}

\section{References}

Autry, L. T. S. (n.d.). Museums are not neutral. Artstuffmatters. Retrieved from https: //artstuffmatters.wordpress.com/museums-are-not-neutral/

Das, S. (2015). Using museum exhibits: An innovation in experiential learning. College Teaching, 63(2), 72-82. http://doi.org/10.1080/87567555.2015.1005044

Gussak, D. (2007). The effectiveness of art therapy in reducing depression in prison populations. International Journal of Offender Therapy and Comparative Criminology, 51(4), 444-460. http://doi.org/10.1177/0306624X06294137

Halperin, J. (2018, April). "It is an unusual and radical act": Why the Baltimore museum is selling blue-chip art to buy work by underrepresented artists. artnetnews. Retrieved from https://news.artnet.com/market/baltimore-museum-deaccession-1274996

Luppi, K. (2014, July). Art museum's guards aren't just security experts - they're also artists. Daily Pilot. Retrieved from https://www.latimes.com/socal/daily-pilot/entertainment/tncpt-et-0801-laguna-art-museum-security-guards-20140731-story.html

Maintaining accessibility in museums. (2009, April). U.S. Department of Justice. Retrieved from https://www.ada.gov/business/museum_access.htm

Packer, J., \& Ballantyne, R. (2002). Motivational factors and the visitor experience: A comparison of three sites. Curator: The Museum Journal, 45(3), 183-198. http: //doi.org/10.1111/j.2151-6952.2002.tb00055.x

Relles, S. R. (2016). Rethinking postsecondary remediation: Exploring an experiential learning approach to college writing. The Journal of Continuing Higher Education, 64(3), 172-180. http://doi.org/10.1080/07377363.2016.1229115

Shrikant, A. (2018, January). How museums are becoming more sensory-friendly for those with autism. Smithsonian Magazine. Retrieved from https://www.smithsonianmag.com/ 
innovation/how-museums-are-becoming-more-sensory-friendly-for-those-with-autism$180967740 /$

Steinhauer, J. (2018, March). Museums have a duty to be political. The Art Newspaper. Retrieved from http://www.theartnewspaper.com/comment/museums-have-a-duty-to-bepolitical 